Published with permission by the ICE under the

\title{
Data analysis and prediction of ground vibrations due to deep vibro-techniques
}

Leong Kam Weng PhD

Business Development Director, Keller ASEAN, Singapore

Mikias M. Yohannes MTech

Principal Engineer, Keller (M) Sdn. Bhd., Kuala Lumpur, Malaysia

(corresponding author: info@keller.com.my) (Orcid:0000-0001-5147-620X)
William Chong MEng

Design Manager, Keller Foundations (S E Asia) Pte Ltd., Singapore

Deep vibro-techniques impart vibrations into the ground to achieve targeted improvement. One of the common geotechnical challenges of these techniques is the question of how vibration attenuates over distance and its effect on nearby structures. In this paper, ground vibration data from several deep vibro-technique projects with different vibrators are analysed. Best-fit estimates of the field data are evaluated through analytical regression, and comparisons of the field data against requirements from some standard codes of practice for admissible vibrations are made. A preliminary estimate of ground vibration levels can be obtained from the empirical relations of vibrator energy and distance. Such an assessment, when coupled with the monitoring and collection of actual field data, should enable further predictions to be more refined. In addition to analysing ground vibration data, predictions of ground vibration and comparisons of theoretical predictions against regressions of the field data are demonstrated. Average estimates of soil profile and strengths are included in the evaluations as well. Suggestions for better predictability of ground vibrations are also given. Moreover, recommendations for safe working distances from existing structures or services are made for different types of vibrators and vibro-techniques.

\section{Notations}

A attenuated amplitude of the vibration (in $\mathrm{m}$ )

$A_{\mathrm{o}} \quad$ unattenuated or at-source amplitude of the vibration (in $\mathrm{m}$ )

c wave speed relevant to the type of wave under consideration (typically, the shear wave velocity for surface monitoring in $\mathrm{m} / \mathrm{s}$ )

$D \quad$ horizontal distance from the source (in $\mathrm{m}$ )

$E_{\mathrm{r}} \quad$ vibrator energy (in J)

$F_{\mathrm{b}} \quad$ building modification factor according to SS 0252 11 (dimensionless)

$F_{\mathrm{m}} \quad$ material modification factor according to SS 0252 11 (dimensionless)

$F_{\mathrm{g}} \quad$ ground modification factor according to SS 025211 (dimensionless)

$f_{\mathrm{o}} \quad$ vibration frequency of the ground next to the depth vibrator (in $\mathrm{Hz}$ )

$f_{\mathrm{g}} \quad$ vibration frequency of the ground at the point where it is being measured or at distance $r$ from the source (in $\mathrm{Hz}$ )

$k \quad$ proportionality constant (dimensionless)

$k_{1}, k_{2}, k_{3}$ proportionality constants per Attewell et al. (1992a, 1992b) (dimensionless)

$M \quad$ mass of the whole vibrator (in $\mathrm{kg}$ )

$m \quad$ mass of the vibrating component or the eccentric weight (in kg)

$n \quad$ attenuation rate (dimensionless)

$P I \quad$ plasticity index of soil (in percentage)

$P P V \quad$ peak particle velocity (in $\mathrm{mm} / \mathrm{s}$ )
$P P V_{\mathrm{R}} \quad$ maximum instantaneous resultant, also the peak vector sum (dimensionless)

$P P V_{\text {srs }} \quad$ square root sum of squares particle velocity or the vector sum of the maximum unidirectional velocities (in $\mathrm{mm} / \mathrm{s}$ )

$P P V_{\text {max }}$ peak component particle velocity (in $\mathrm{mm} / \mathrm{s}$ )

$P P V_{\mathrm{Z}} \quad$ vertical component of the particle velocity selected for assessment (in $\mathrm{mm} / \mathrm{s}$ )

$q_{\mathrm{c}} \quad$ cone tip resistance of cone penetration tests (in MPa)

$R^{2} \quad$ coefficient of determination of best fits

$r \quad$ radial or slope distance from the source (in $\mathrm{m}$ )

$t_{\mathrm{o}} \quad$ initial instance of a vibration duration (in s)

$t_{\mathrm{n}} \quad$ final instance of a vibration duration (in s)

$r_{\mathrm{o}} \quad$ radial or slope distance close to the vibration source (in $\mathrm{m}$ )

$v_{\mathrm{L}, i} \quad$ longitudinal particle velocity at a given instant (in $\mathrm{mm} / \mathrm{s}$ )

$v_{\mathrm{R}, i} \quad$ radial particle velocity at a given instant, facing towards the source (in $\mathrm{mm} / \mathrm{s}$ )

$v_{\mathrm{V}, i} \quad$ vertical particle velocity at a given instant (in $\mathrm{mm} / \mathrm{s}$ )

$v_{\mathrm{V}, \max }$ maximum particle velocity in the vertical direction, also equal to $P P V_{\mathrm{Z}}$ (in $\mathrm{mm} / \mathrm{s}$ )

$v_{\mathrm{o}} \quad$ vibration imparted to the soil close to the vibration source (at $r_{\mathrm{o}}$ distance, in $\mathrm{m} / \mathrm{s}$ )

$v_{\mathrm{vb}} \quad$ rotational velocity of the vibrator (in $\mathrm{m} / \mathrm{s}$ )

$W_{\mathrm{r}} \quad$ rated energy of the vibration source (in J)

$\alpha \quad$ material/soil damping coefficient (dimensionless)

$\gamma \quad$ geometrical damping coefficient (dimensionless)

$\eta \quad$ material damping loss factor (dimensionless) 
velocity conversion factor to account for energy transfer losses (dimensionless)

$\pi \quad$ mathematical constant, approximately 3.142

(dimensionless)

$\sigma_{\text {std }} \quad$ standard deviation of a data set (same units as the data)

$\Psi$ proportionality constant that considers vibration transfer efficiency, the adjustment in the mass of vibrator and adjustment in the distance from the source (dimensionless)

\section{Introduction}

As more and more structures continue to be built in the proximity of other existing structures and amenities, construction-related impact to structures becomes a vital topic of interest. Construction-related vibrations are one such source of potential impact, as these vibrations can cause unintended ground deformation that can potentially lead to structural dilapidation.

Construction activities that utilise impact energy or vibratory energy for their execution are the usual sources of ground vibrations. These activities include numerous deep foundation and ground improvement techniques, such as pile driving, sheet piling installation, blasting, percussion drilling, dynamic compaction, dynamic replacement, surface compaction, rapid impact compaction and deep vibro-techniques.

This paper discusses the peak particle velocity $(P P V)$ that is generated from the installation of deep vibro-technique solutions. Deep vibro-techniques, as per BS EN 14731 (BSI, 2005), are ground improvement products that are installed using a depth vibrator. The depth vibrator transmits the compaction effort to the ground as it progresses down during penetration and as it withdraws while compacting the granular materials. Particular emphasis is made on two ground improvement methods: vibroreplacement and vibro-compaction. Vibro-replacement or vibrostone column is a ground improvement method where compacted granular columns are installed to boost the bearing capacity, shear strength, stiffness and drainage properties of weak soils. Vibrocompaction is a ground improvement method that is used to densify loose cohesionless layers.

\section{Existing models for prediction of ground vibrations method}

The estimation and prediction of ground vibrations from construction activities have been studied since the 1960s. Different sources of ground-borne vibrations have been studied. Because of the abundance of field observations and experimental data, the most extensively investigated construction activities are blasting activities and the driving of piles using impact and vibratory hammers. These two activities are also among the most common construction activities across the world. Table 1 gives a summary of the different approaches to predict $P P V$. Because deep vibro-techniques have not been extensively studied and as the ground vibrations from pile driving actions are similar to those of deep vibro-techniques, here, more emphasis is made on pile driving studies.

Most of the prediction methods rely on the term $D / \sqrt{W_{\mathrm{r}}}$ or scaled distance (in $\mathrm{m} \cdot \mathrm{J}^{-0.5}$ ), which is a normalisation that is especially useful when comparing different energy ratings, where $D$ is the

Table 1. Empirical and semi-empirical approaches of vibration predictions of foundation installation activities, such as piling and vibrostone column works

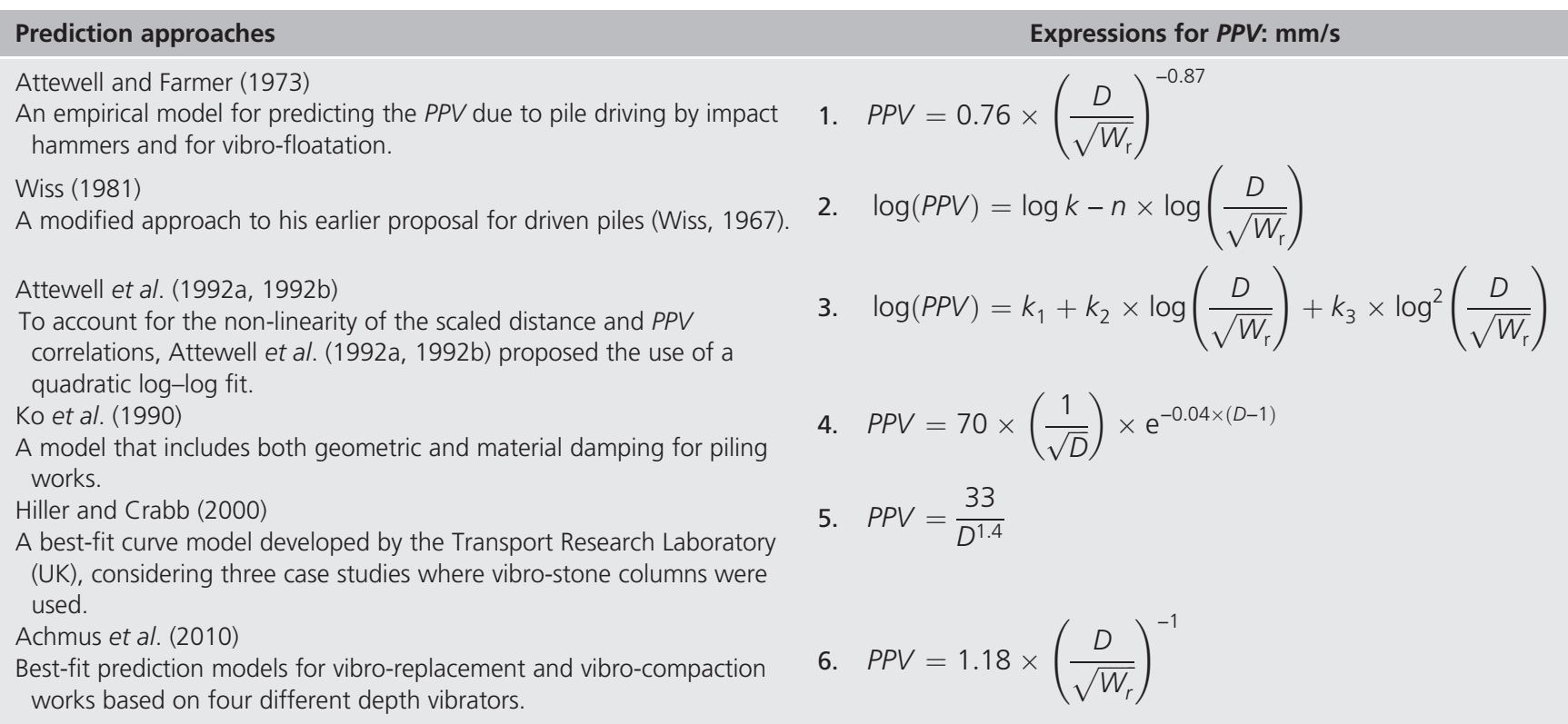

Note: some of the expressions have been altered for consistency in using the same units for the parameters considered in the expressions (all input in metre, kilogram, second (MKS) units and PPV given in $\mathrm{mm} / \mathrm{s}$ ) 
distance from the source of the vibration to the measurement point (in $\mathrm{m}$ ) and $W_{\mathrm{r}}$ is the rated energy of the vibration source (in J). It is also essential to understand that these existing models do not account for the soil types, stiffness and ground conditions. These are all considered to be site-specific and addressed by the curve-fitting constants for site and vibration source energy levels.

Attewell and Farmer (1973) initially proposed an empirical model that predicted the $P P V$ due to pile driving by impact hammers and for vibro-floatation. The approach, which is a scaled-distance empirical approach, considers the effect of distance and energy on the PPV generated. Attewell and Farmer (1973) argued that the values of 1.50 for the proportionality constant and 1.00 for the coefficient of geometric damping are more suited for a conservative approximation, although 0.76 and 0.87 were respectively evaluated from curve-fitting. To account for the nonlinearity of the scaled distance and $P P V$ correlations, Attewell et al. (1992a, 1992b) later proposed the use of a quadratic log-log fit. They used the power law to propose the relationship, as shown in Equation 3 of Table 1, and defined the parameters $k_{1}, k_{2}$ and $k_{3}$ as proportionality constants that depend on the soil conditions.

Another similar approach was observed by Wiss (1981), who extended his initial empirical predictive model (Wiss, 1967) for driven pile applications as per Equation 2. He did not define any specific values for the proportionality constant $(k)$ or the attenuation rate $(n)$. On the basis of numerous successive field observations and literature, the typical range of the attenuation rate is between 0.80 and 1.70 , and it varies because of different soil conditions.

The previous empirical scaled-distance approaches do not consider the effect of material damping. An exception to these approaches was that of Ko et al. (1990), who proposed a driven pile model that includes both geometric and material damping, as per Equation 4.

For ground vibrations due to deep vibro-techniques, a documented study of the ground vibrations is found in the work of Hiller and Crabb (2000), which was also included in BS 5228-2:2009 (BSI, 2008). Documented field vibrations from three vibro-replacement projects in the United Kingdom were assessed to give the best-fit curve, as shown in Equation 5. Achmus et al. (2010) also discussed the ground vibrations caused by vibro-compaction and vibroreplacement works. Their study encompasses depth vibrators with energy ratings in the range of 700 to $6000 \mathrm{~J}$. Achmus et al. (2010) followed the recommendations of Attewell and Farmer (1973) for the linear regression of their data and consider an attenuation rate of unity. They proposed proportionality constants for vertical and horizontal vibrations, in addition to the resultant $P P V$, which is shown in Equation 6. Although Attewell et al. (1992a, 1992b) recommended an upper bound safety threshold of one standard deviation from the best fit ( $84 \%$ confidence level against exceedance), Achmus et al. (2010) have reasoned for an upper limit of two times the standard deviation (97.7\% confidence level against exceedance).
All the discussed studies, being primarily derived from pile driving data sets, do not appropriately depict the wave generation and propagation of deep vibro-technique applications. The predictive models are either proper in the far-field but not as good in the nearfield estimations or vice versa. The dependency of the vibration intensity on the type of vibrator (i.e. operating frequency, power rating and mass) is also not adequately captured with the existing models. Moreover, the nature of deep vibro-techniques' wave propagation through different ground conditions and associated attenuation due to damping is another area that most of the existing models do not sufficiently cover. Lastly, the safety considerations for safe operating distance calculations have not been covered in most of the existing studies. The development of a semi-empirical deep vibrotechnique prediction tool that addresses the shortcomings of applying the existing models therefore becomes useful.

\section{Evaluation of field measurements}

It is vital to be able to predict the potential impact that structures can experience because of construction vibrations. This helps not only in predicting the likelihood of structural damage but also in establishing safety measures that would safeguard existing structures (Chua et al., 2009).

Field measurements from deep vibro-techniques were done using geophones with self-triggering and continuous monitoring facilities that can analyse triaxial velocity, acceleration and displacement. The method follows the recommendations of the Building Research Establishment Digest 403 (BRE, 1995) and BS 7385 (BSI, 1993). The devices were chosen to have $P P V$ range up to about $250 \mathrm{~mm} / \mathrm{s}$, with a resolution of 0.010 to $0.125 \mathrm{~mm} / \mathrm{s}$. Figures 1 and 2 show the method of field instrumentation and monitoring that was used.

In this study, vibratory sources with different intensities were investigated. Three different types of depth vibrators for stone column works were monitored in multiple sites. The soils targeted by the vibro-replacement works in most of the sites were strongly layered and ranged from very soft to stiff, plastic clayey and silty soils (plasticity index $(P I)=30-60 \%$ ), having cone tip resistances of $q_{\mathrm{c}}=0.2$ to $1.5 \mathrm{MPa}$. The depth of treatment was in the range of 8 to $20 \mathrm{~m}$. For vibro-compaction works, one type of vibrator was monitored and investigated. The monitoring was generally done in reclamation sites, where very loose to medium dense sandy soils dominate (typical cone tip penetration values of $q_{\mathrm{c}}=4-12 \mathrm{MPa}$ ). During the data collection, the maximum depth of treatment for the vibro-compaction works was approximately $30 \mathrm{~m}$.

The details of the vibrator types that are covered in this paper and their corresponding energy levels are as summarised in Table 2. The energy levels of the vibrators in this study fall within the range of those that were studied by Achmus et al. (2010), whereas the energy levels of the vibrators studied by Hiller and Crabb (2000) were not specified.

A sample field vibration measurement is shown in Figure 3, where the three-dimensional (3D) components of the $P P V$ are 


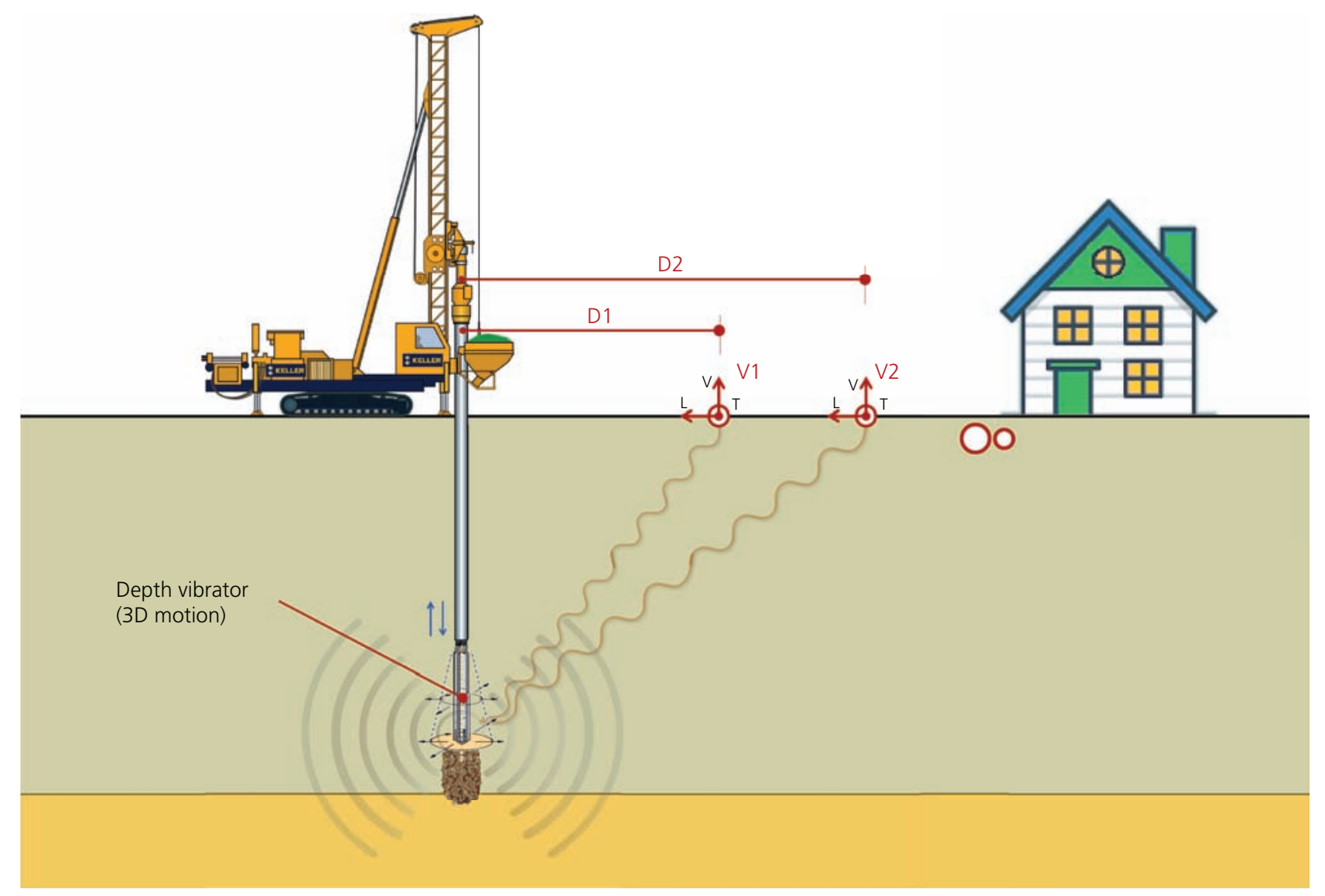

Figure 1. Schematic diagram of the deep vibro-technique's wave propagation and field instrumentation

plotted as recorded over time, and the corresponding plot of velocity against frequency is also shown. From the sample record for a VR-B vibrator, it is evident that regardless of the measured distance, the majority of the vibration data are at or around the vibrator frequency $(50 \mathrm{~Hz})$.

A total of close to 1000 data points were collected from the field measurements. For all the data, the distance from the source and the three axes' $P P V$ (vertical, radial and transverse) were recorded, as shown in Figures $1-3$. The $P P V$ that is considered for the assessments is the maximum instantaneous resultant $P P V$ $\left(P P V_{\mathrm{R}}\right)$, which is also known as the peak true vector sum velocity (AASHTO, 2009) at any given instant during the vibration from the initial time $t_{\mathrm{o}}$ to the final time $t_{\mathrm{n}}$, and is defined as follows:

7.

$$
P P V_{R}=\max \left({\sqrt[t n]{v_{R, i}^{2}+v_{V, i}^{2}+v_{L, i}^{2}}}^{i=t_{0}}\right)
$$

This approach is similar to that used by Ho and Tan (2003) and Ekanayake et al. (2013). It is also not the same as the value of the square root sum of squares, $P P V_{\text {srss, }}$ which is a conservative approach of taking the vector sum of the maximum unidirectional velocities, which usually occur at different instants. Several codes of practice, however, refer to the peak component particle velocity $\left(P P V_{\max }\right)$, which is the maximum value of any one of the three orthogonal component particle velocities measured during a given time interval (e.g. BS 7385 (BSI, 1993)). Table 3 gives a comparison of the commonly referred to and relevant codes of practice for evaluating the structure impact risk and which $P P V$ parameters are considered in each. Other frequent references, such as the US Bureau of Mines Report of Investigation 8507 (USBM RI 8507; Siskind et al., 1980) and Indian Directorate General of Mines Safety guidelines (DGMS, 1997), are not included as these are applicationspecific (i.e. blasting works).

Another factor that all codes of practice recognise is that the structural damage potential is contingent on the frequency of the ground vibration. The choice of peak $P P V$ or the vector sum should also be viewed with respect to the frequency of vibration. Figure 4 shows how the peak component particle velocity in the vertical dimension $\left(P P V_{\mathrm{Z}}\right)$ measures up to the $P P V_{\mathrm{R}}$ for the selected types of vibrators. As it is made evident from the plot, the peak instantaneous particle velocity $\left(P P V_{\mathrm{R}}\right)$ consideration is valid and affords a slight conservativeness in the ensuing calculations. Similar observations were made for pile driving vibrations as per Hamidi et al. (2018). It 


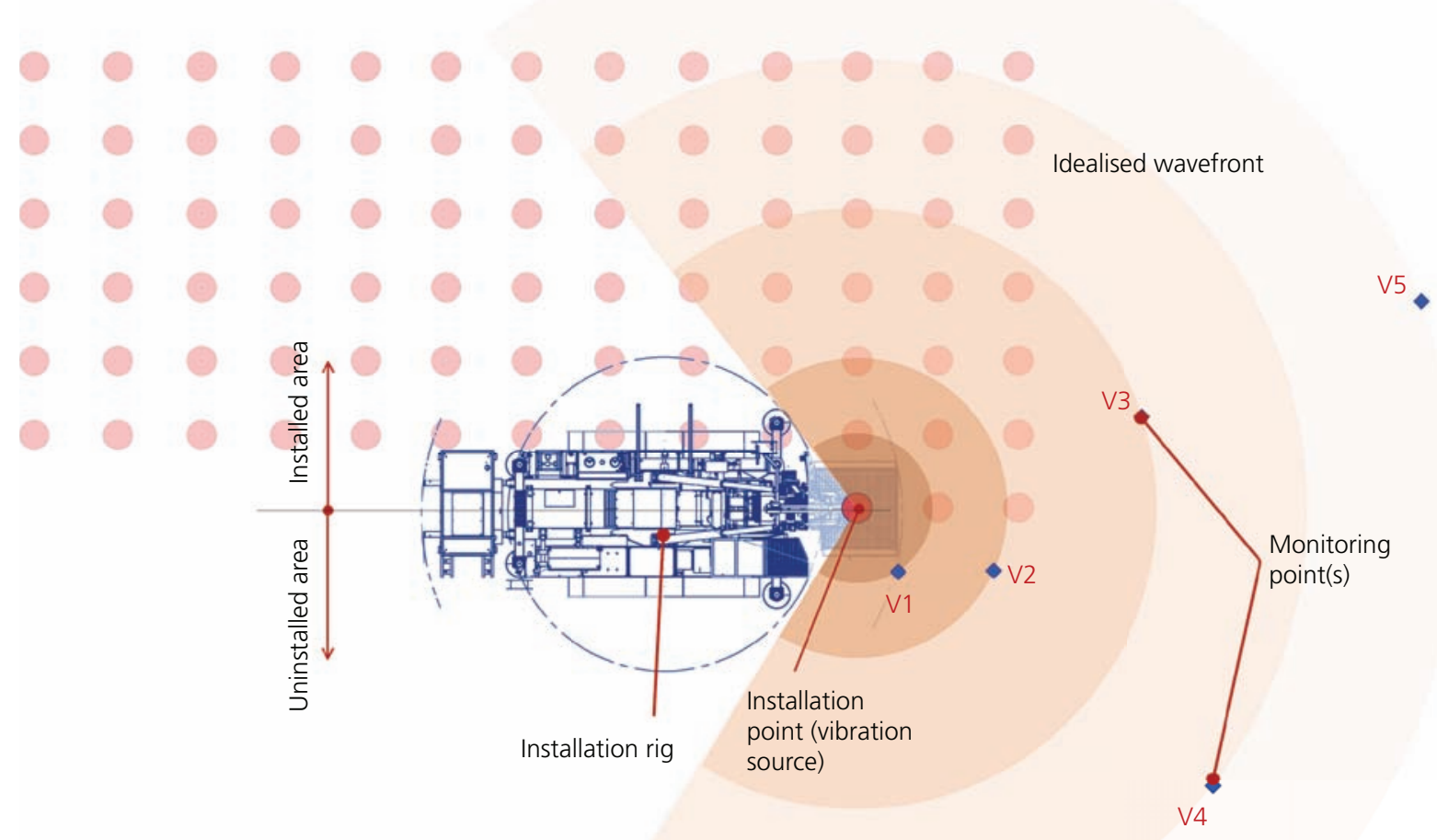

Figure 2. Illustration of the placement of monitoring points relative to the installation point

Table 2. Depth vibrators considered in this study (courtesy of Keller Holding GmBH)

\begin{tabular}{lccccccc} 
Vibrators & $\begin{array}{c}\text { Operating } \\
\text { frequency: Hz }\end{array}$ & $\begin{array}{c}\text { Rated } \\
\text { power: kW }\end{array}$ & $\begin{array}{c}\text { Vibrator } \\
\text { mass: } \mathbf{k g}\end{array}$ & $\begin{array}{c}\text { Centrifugal } \\
\text { force: } \mathbf{k N}\end{array}$ & $\begin{array}{c}\text { Maximum } \\
\text { energy: J }\end{array}$ & $\begin{array}{c}\text { Field } \\
\text { data: } \boldsymbol{N}\end{array}$ \\
\hline VR-A & 50 & 50 & 2000 & $156-165$ & 1000 & 371 \\
VR-B & 50 & 55 & 1700 & 165 & 1100 & 86 \\
VR-C & $50-60$ & 70 & 1700 & $157-226$ & $1150-1400$ & 73 \\
VC-A & 30 & 120 & 2450 & $200-340$ & 4000 & 451
\end{tabular}

was also observed that the $P P V_{\mathrm{Z}}$ component diminishes at points further away from the source and the radial component becomes prominent. This is in agreement with Gutowski and Dym (1976), who argued that the body waves diminish at a faster rate from the source than Rayleigh waves.

The applications of the different vibration prediction theories using the field test results are shown in Figure 5. The $P P V_{\mathrm{R}}$ values for the VR-A vibrators are plotted, and best fits using the different approaches listed in Table 1 are included. The two plots in Figure 5 are plots of peak instantaneous $P P V$ against the actual distance (Figure 5(a)) and against the logarithm of the scaled distance (Figure 5(b)). In this paper, the inverse of the scaled distance has been chosen for the sake of consistency of units (in MKS-SI units, or $\mathrm{J}^{0.5} \cdot \mathrm{m}^{-1}$ ) and to take account of the negative rate of attenuation ( $n$, instead of $-n)$. This is also in accordance with Attewell et al. (1992a, 1992b).

On the basis of the collected information and the corresponding plots from the different approaches, Figure 5(a) shows that the modified approaches of Attewell and Farmer (1973) and Ko et al. (1990) are the upper bound models. The Ko et al. (1990) 


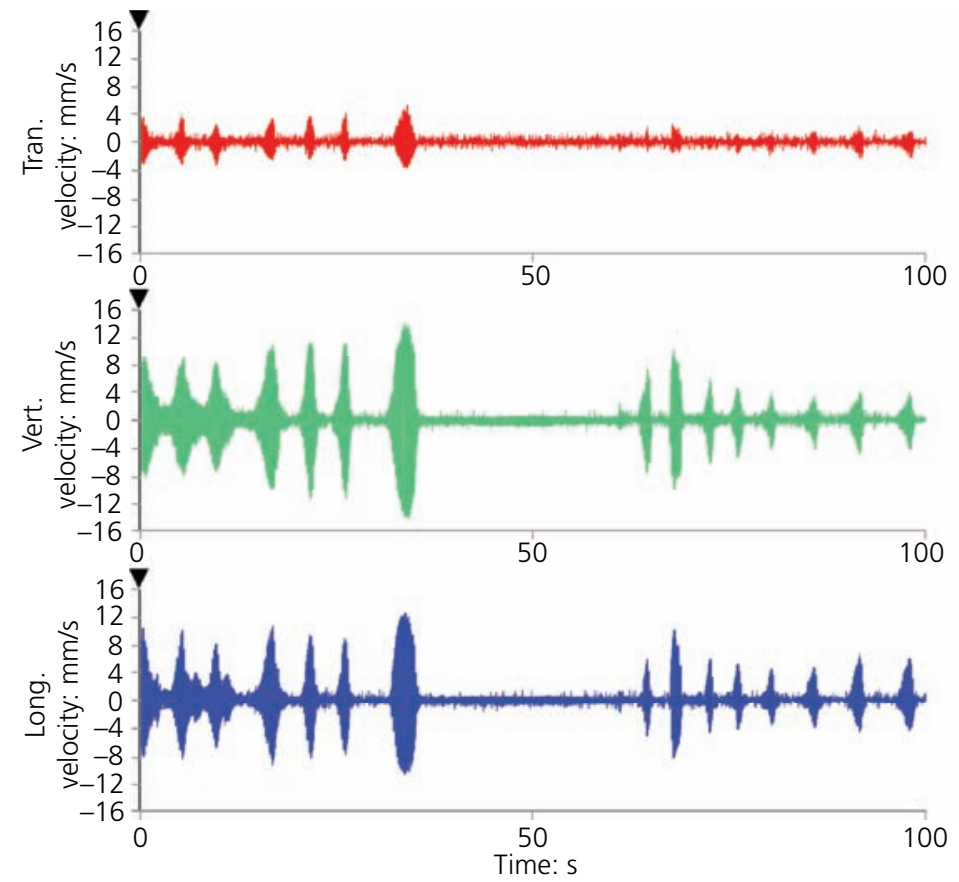

Swiss piling standard SN 340 312a velocity versus frequency (zero crossing)

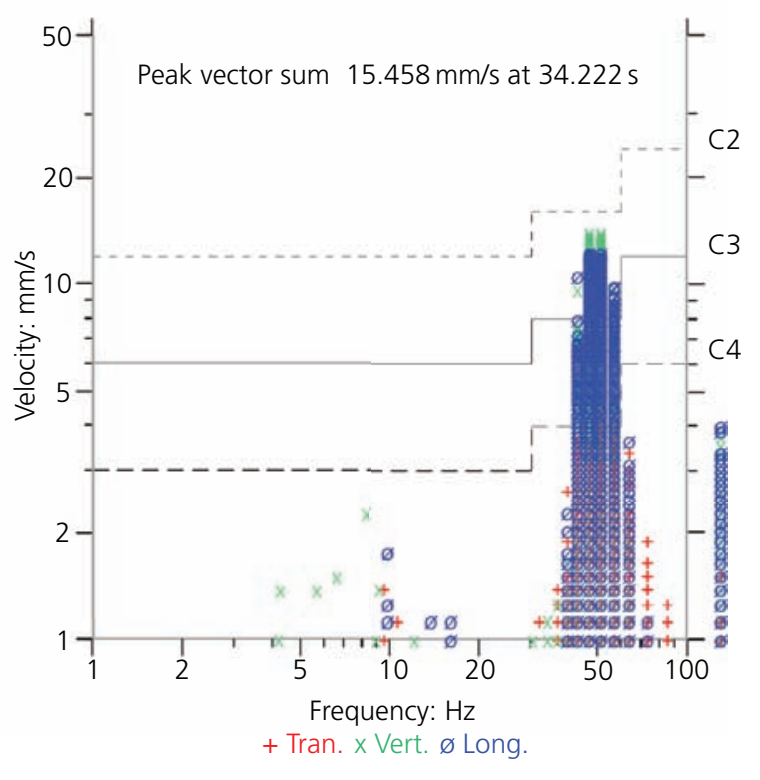

Figure 3. Typical post-processed field vibration measurements from a vibro-replacement site (VR-C vibrator, with the sensor at $5.0 \mathrm{~m}$ ), including three-dimensional (3D) component plots and measured frequencies against SN 640 312a (SNV, 1992) recommendations

Table 3. Definition of PPVs according to different codes of practice

\begin{tabular}{|c|c|c|}
\hline Code of practice & PPV component considered & Remarks \\
\hline BS 7385-2 (UK; BSI, 1993) & $\begin{array}{l}\text { Peak component of } P P V \\
P P V=\max \left\{V_{L, \text { max }}, V_{V, \text { max }}, V_{R, \text { max }}\right\}\end{array}$ & Limit for cosmetic damage of structures due to transient vibrations \\
\hline DIN 4150-3 (German; DIN, 2016) & $\begin{array}{l}\text { Peak component of } P P V \\
P P V=\max \left\{V_{L}, \max , V_{V}, \max , V_{R, \text { max }}\right\}\end{array}$ & $\begin{array}{l}\text { For continuous vibrations, the peak PPV in the horizontal direction is } \\
\text { considered }\end{array}$ \\
\hline SS 025211 (Swedish; SIS, 1999) & $\begin{array}{l}\text { Peak vertical velocity } \\
P P V=V_{\mathrm{V}, \max } \times F_{\mathrm{b}} \times F_{\mathrm{m}} \times F_{\mathrm{g}}\end{array}$ & $\begin{array}{l}\text { The PPV is further corrected by applying building, material and ground } \\
\text { modification factors }\end{array}$ \\
\hline SN 640-312a (Swiss; SNV, 1992) & $\begin{array}{l}\text { Peak vertical velocity } \\
P P V=V_{V}, \max \end{array}$ & $\begin{array}{l}\text { Recommendations for four categories of structures are given on the basis } \\
\text { of different types of vibration sources }\end{array}$ \\
\hline
\end{tabular}

approach gives a better upper bound approximation in terms of exceedance, whereas the effect of material damping in the farfield is a stark differentiator. Figure 5(b) shows the solution of Attewell et al. (1992a) on the log scaled distance plot. The onesigma and two-sigma brackets of the quadratic best fits are also included in the plot. From the plot, the recommendations of Achmus et al. (2010) to use the upper two-sigma bracket appears valid from safety and exceedance rate points of view. Comparing the two best fits in Figure 5 - that is, Wiss (1981) and Attewell et al. (1992a), which are also denoted using shaded areas in the plots for $50 \%$ exceedance rate - it is observed that the quadratic fit has a lower coefficient of determination $\left(R^{2}\right.$ of 0.22 against 0.19 , respectively). As the data for the VR-A vibrators are from various sites, the lower $R^{2}$ can be attributed to significant differences in soil and vibrator operating conditions. Nevertheless, and albeit being an empirical approach, it goes to show that the quadratic best fit has its own statistical merits when diverse conditions are assessed collectively.
Similarly, plots of the $P P V_{\mathrm{R}}$ with respect to distance and scaled distances are shown in Figures 6-8 for the other vibrators listed in Table 2. It is interesting to note that for the other vibrator data sets, the coefficient of determination $\left(R^{2}\right)$ of both the linear and quadratic fits is relatively similar. For vibro-replacement works (vibrators VR-B and VR-C), the data set is from sites of relatively similar ground conditions. Hence, the variation to be expected would not be overly significant. Similarly, for the VC-A, the data set is typically done in a more or less similar type of soils (i.e. loose reclaimed sands).

Figures 5-8 show that the deep vibro-technique vibrations are not suitably captured by the existing tools, although for some data sets, the tools may give fair estimations. Relatively better estimates are obtained using Attewell et al. (1992a, 1992b); however, the method does not have consistent results as the vibrator type changes. It is also a purely empirical approach that is independent of some of the vibrator details. Therefore, a new approach that considers these 
Data analysis and prediction of ground

vibrations due to deep vibro-techniques

Weng, Yohannes and Chong

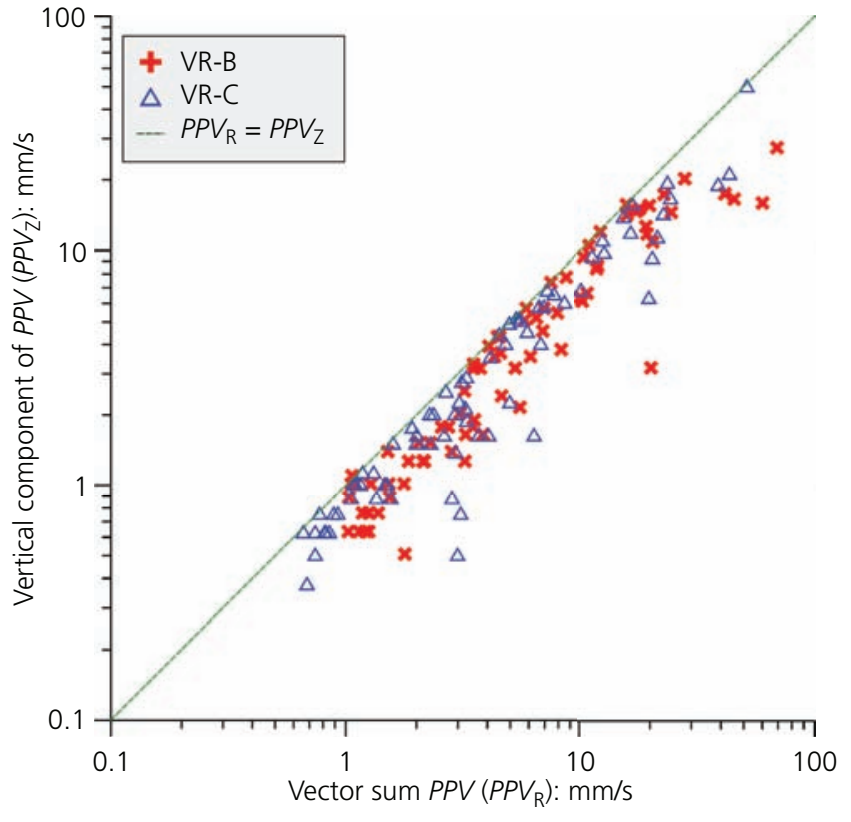

Figure 4. Comparison of $P P V_{R}$ and $P P V_{Z}$ for VR-B and VR-C vibrators

shortcomings while incorporating some of the vibrator and ground properties into the estimation tool is vital.

\section{Vibration attenuation and effect on nearby structures}

Semi-empirical approach for depth vibrators

Gutowski and Dym (1976) indicate that Rayleigh waves take up $67 \%$ of the vibration energy, whereas $33 \%$ of the energy is converted into body waves. The implication of this is that at the surface (where the vibration measurement is typically done and where structures are located), the dominant vibration component will be the Rayleigh waves. Moreover, the soil near the source would primarily experience the body waves emanating from the source, although Deckner et al. (2017) have shown that Rayleigh waves develop very close to the source. During the transfer of waves from the source to the surface, the vibration gets attenuated as a result of material and geometrical damping. The attenuated vibration can be expressed in terms of amplitude as follows (Mintrop, 1911), putting the effect of damping into consideration:

8. $\frac{A}{A_{\mathrm{o}}}=\left(\frac{r_{\mathrm{o}}}{r}\right)^{\gamma} \times \exp \left(-\alpha \times\left(r-r_{\mathrm{o}}\right)\right)$

where $A$ is the attenuated vibration amplitude at a radial distance $r$ from the source, $A_{\mathrm{o}}$ is the excitation amplitude of the soil particles close to the source, or at a distance $r_{\mathrm{o}}, \gamma$ is the geometrical damping coefficient, and $\alpha$ is the material damping coefficient.

Although the source vibration has a sinusoidal vibration, the ground response is a pseudo-steady state vibration (Long, 1989; Svinkin, 2004). The ground response depends on a number of factors, such as the intensity of the source, the depth of the source, the distance from the source, the stiffness of the ground, the depth of the groundwater table and time dependency of the loading. The rated vibration energy $E_{r}$ of a harmonically vibrating depth vibrator can be expressed as:

9. $E_{r}=\frac{m \times v_{v b}^{2}}{2}$

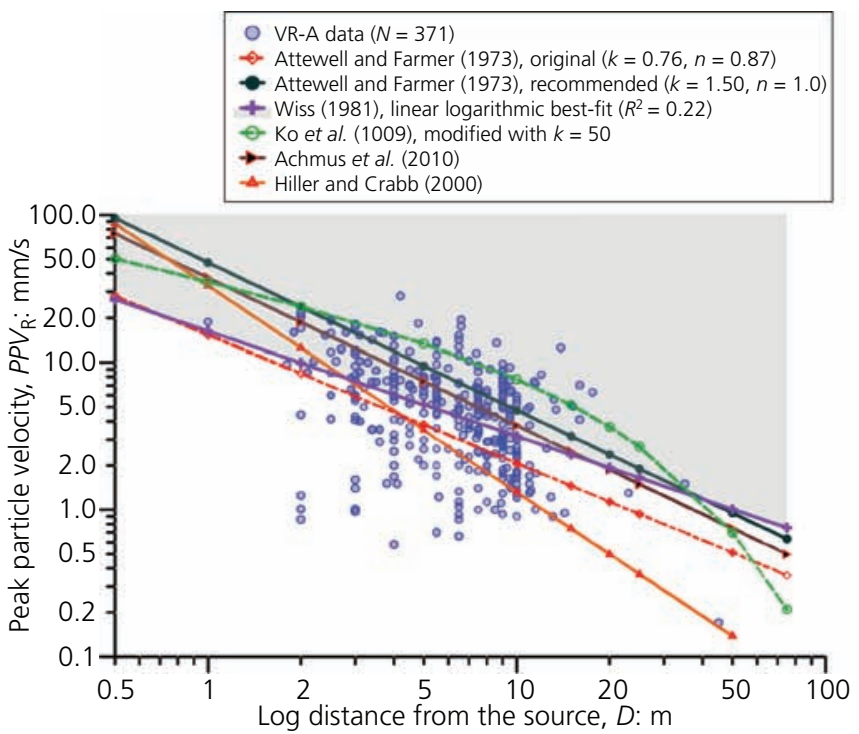

(a)

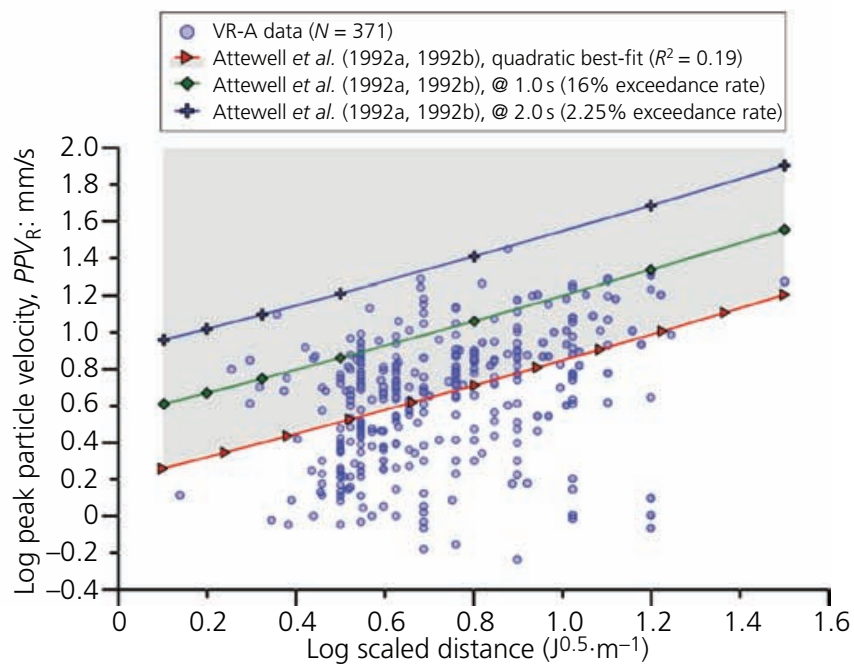

(b)

Figure 5. Plot of VR-A vibration data (a) against distance from the source and (b) against the logarithm of scaled distance 


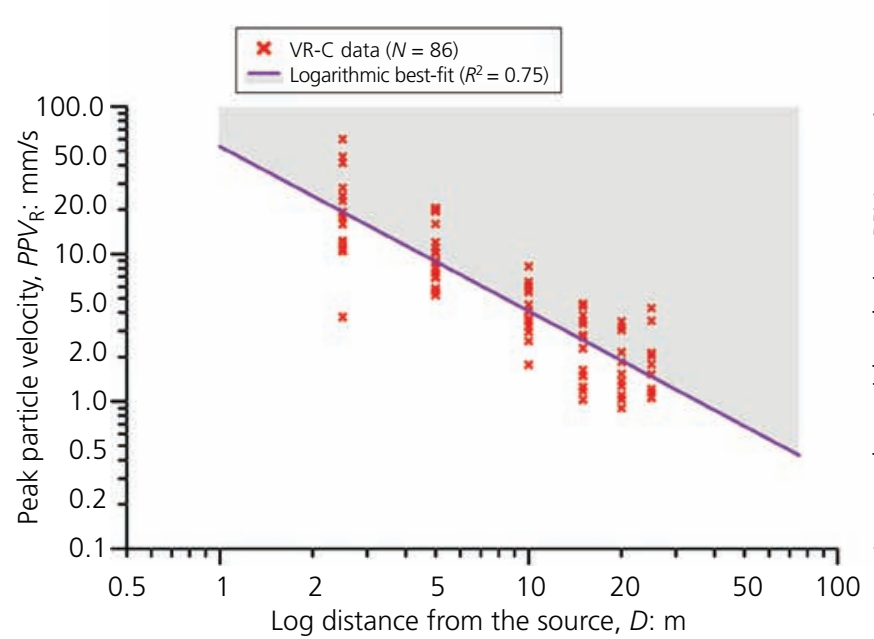

(a)

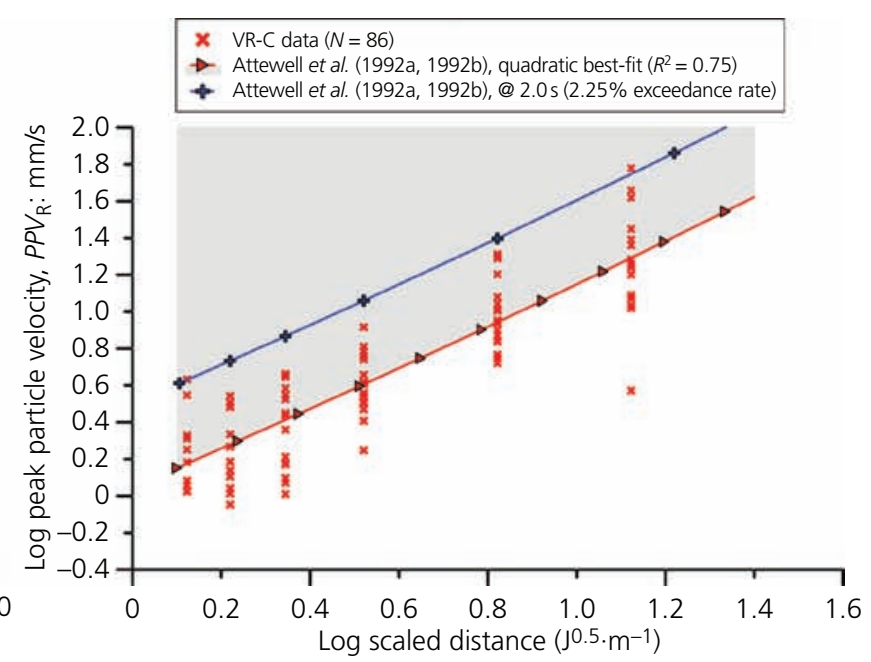

(b)

Figure 6. Plot of VR-B vibration data (a) against distance from the source and (b) against the logarithm of scaled distance

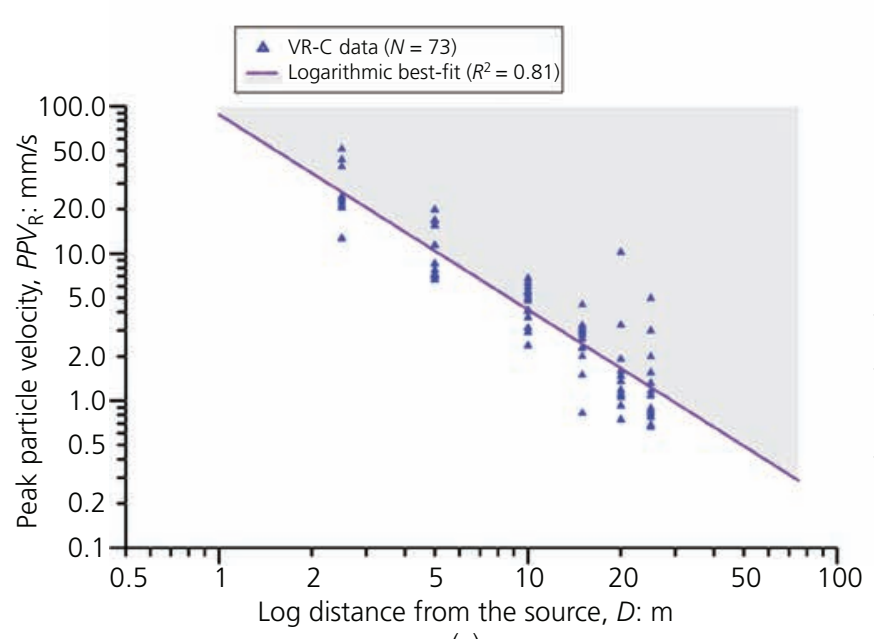

(a)

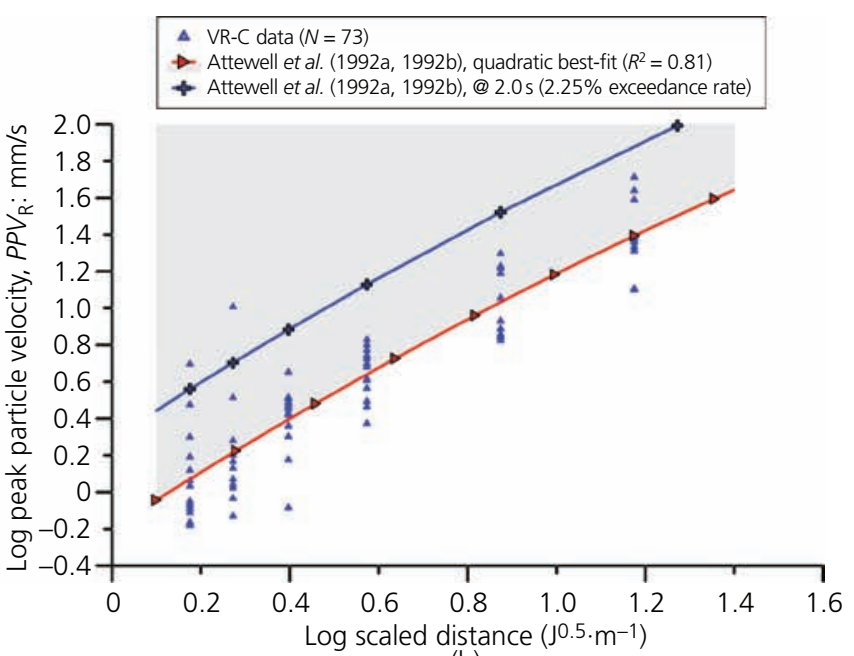

(b)

Figure 7. Plot of VR-C vibration data (a) against distance from the source and (b) against the logarithm of scaled distance

where $m$ is the mass of the vibrating component or the eccentric weight, and $v_{\mathrm{vb}}$ is the rotational velocity of the vibrator. The vibrator velocity can now be related to the vibration imparted into the ground by:

10. $v_{o}=\kappa \times v_{v b}=2 \pi \times f_{o} \times A_{o}$

where $\kappa$ is the velocity conversion factor that considers the energy transfer losses due to various conditions and $f_{\mathrm{o}}$ is the vibration frequency of the ground just next to the depth vibrator. For practical applications, the soil particles next to the vibrator will be excited about the same frequency as the source. Even the ground vibration frequency $f_{\mathrm{g}}$ is observed to be closely similar to the source frequency (refer to Figure 2). Therefore, Equation 8 can be rewritten as

11a. $\frac{P P V}{v_{\mathrm{o}}}=\left(\frac{r_{\mathrm{o}}}{r}\right)^{\gamma} \times \exp \left(-\alpha \times\left(r-r_{\mathrm{o}}\right)\right)$

11b. $\frac{P P V}{\kappa \times v_{v b}}=\left(\frac{r_{\mathrm{o}}}{r}\right)^{\gamma} \times \exp \left(-\alpha \times\left(r-r_{\mathrm{o}}\right)\right)$

Therefore, regardless of the vibrator energy, the velocity ratio $\left(P P V / v_{\mathrm{o}}\right)$ can be given by Equation 11a. This ratio is only dependent on the distance from the source, the geometric damping factor and 


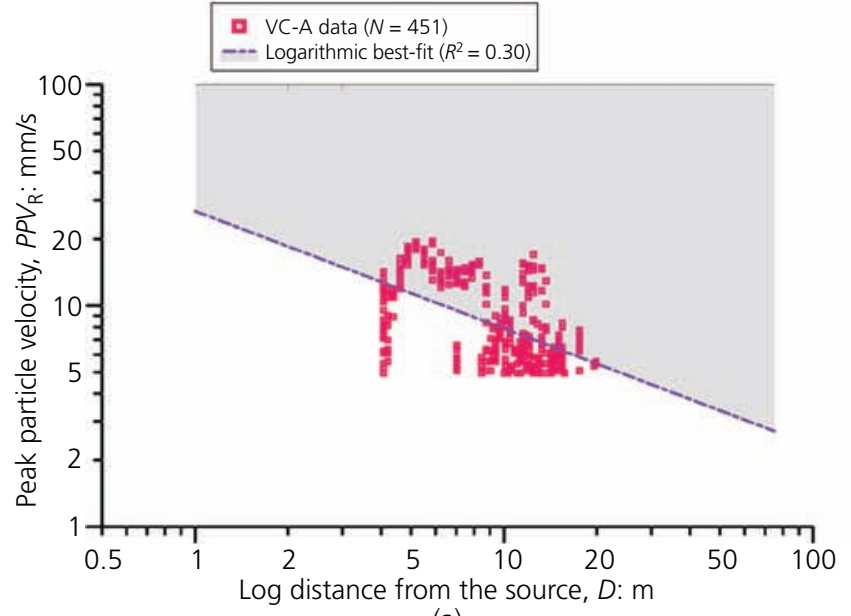

(a)

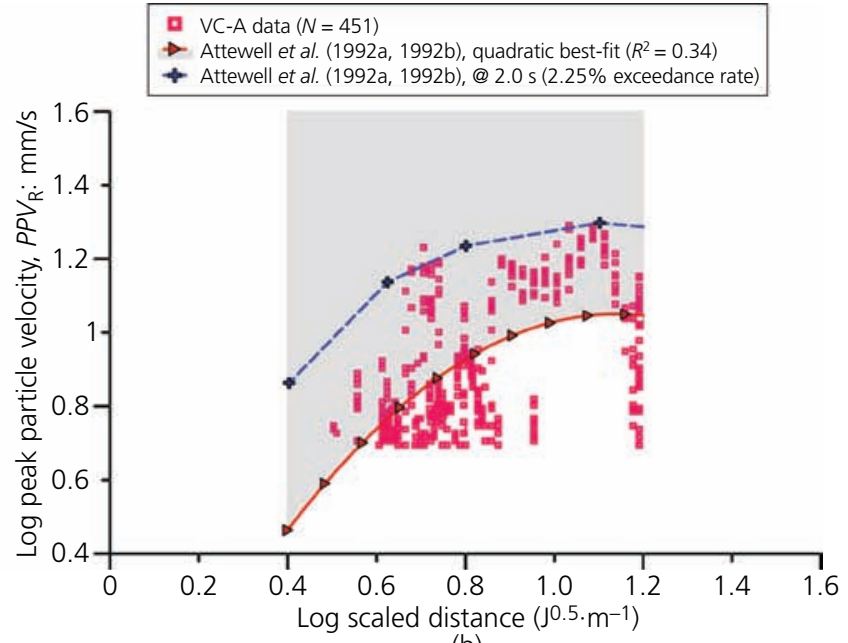

(b)

Figure 8. Plot of VC-A vibration data (a) against distance from the source and (b) against the logarithm of scaled distance

soil conditions. Finally, the $P P V$ (or $P P V_{\mathrm{R}}$ ) can be given in terms of the vibrator energy as (all units in the MKS system)

$$
P P V_{\mathrm{R}}=\kappa \times \sqrt{\frac{2 E_{\mathrm{r}}}{m}} \times\left(\frac{r_{\mathrm{o}}}{r}\right)^{\gamma} \times \exp \left(-\alpha \times\left(r-r_{\mathrm{o}}\right)\right)
$$

Setting the reference distance $r_{\mathrm{o}}$ as 1 and considering that the vibrator eccentric mass $m$ is always a linear proportion of the total vibrator mass $M$, Equation 12 can be simplified as

$13 a$.

$$
P P V_{\mathrm{R}}=\Psi \times \sqrt{\frac{E_{\mathrm{r}}}{M}} \times D^{-\gamma} \times \exp (-\alpha \times D)
$$

or in a dimensionless, normalised form as

13b. $\frac{P P V_{\mathrm{R}}}{\sqrt{E_{\mathrm{r}} / M}}=\Psi \times D^{-\gamma} \times \exp (-\alpha \times D)$

The constant $\Psi$ can be taken as a proportionality constant that puts into consideration the efficiency of vibrator energy transfer, consideration of the vibrator mass rather than the eccentric mass, the effect of change in distance from radial distance to projected distance from the source, the effect due to the removal of the reference distance $r_{\mathrm{o}}$ from the expression and other constants.

As Gutowski and Dym (1976) and Long (1989) have shown, the dimensionless coefficient of geometric damping $(\gamma)$ will be dependent on the location of the source and type of waves under consideration. It also typically ranges from 0.5 to 2.0 depending on the type of wave. For surface measurements, because the dominant vibrations will be the Rayleigh waves, a value of 0.5 can be adopted for $\gamma$. Woods and Jedele (1985) have shown that the material damping factor, $\alpha$, for different soils is frequency dependent, and at $50 \mathrm{~Hz}$, the typical range of damping factors is from $0.005 \mathrm{~m}^{-1}$ (hard soils and competent rock) to $0.30 \mathrm{~m}^{-1}$ (weak or soft soils). Equation $13 \mathrm{~b}$ can now be simplified by taking the natural logarithm of both sides of the equation.

13c.

$$
\ln \left(\frac{P P V_{R}}{\sqrt{E_{\mathrm{r}} / M}}\right)=\ln \Psi-0.5 \times \ln D-\alpha \times D
$$

Because the normalised $P P V$ value (or $P P V_{\mathrm{R}} / \sqrt{E_{\mathrm{r}} / M}$ ) can be evaluated from the measured $P P V \mathrm{~s}$ and the vibrator information, generalised values of the other two unknowns in the equation (namely, $\Psi$ and $\alpha$ ) can be evaluated from a regression analysis. Figure 9 shows the plot of the logarithm of the normalised $P P V$ against the distance from the source for the four different types of vibrator data sets.

It can be observed that there are a lot of overlaps between the data clusters. This indicates that the evaluated relationship following Equation $13 \mathrm{c}$ has good reliability. The plot also shows a logistic regression line taking the form of Equation 13c. The two constants from the regression (A and $\mathrm{B}$ ), give the generalised values of the unknowns of Equation 13c. $\Psi$ corresponding to the best fit ( $50 \%$ probability of exceedance) is estimated to be around 0.020 to 0.025 (all in MKS units). Applying regression on all the data set, the material damping factor $\alpha$ is observed to be approximately $0.030 \mathrm{~m}^{-1}$, which is in good agreement with Woods and Jedele (1985) and for the soils typically treated with deep vibro-techniques. Amick and Gendreau (2000) also reported similar values for intermediate-strength soils in their summary from different literature. The expression for the general best-fit curve shown in Figure 9, which take the form of Equation 13b, 
Data analysis and prediction of ground

vibrations due to deep vibro-techniques

Weng, Yohannes and Chong

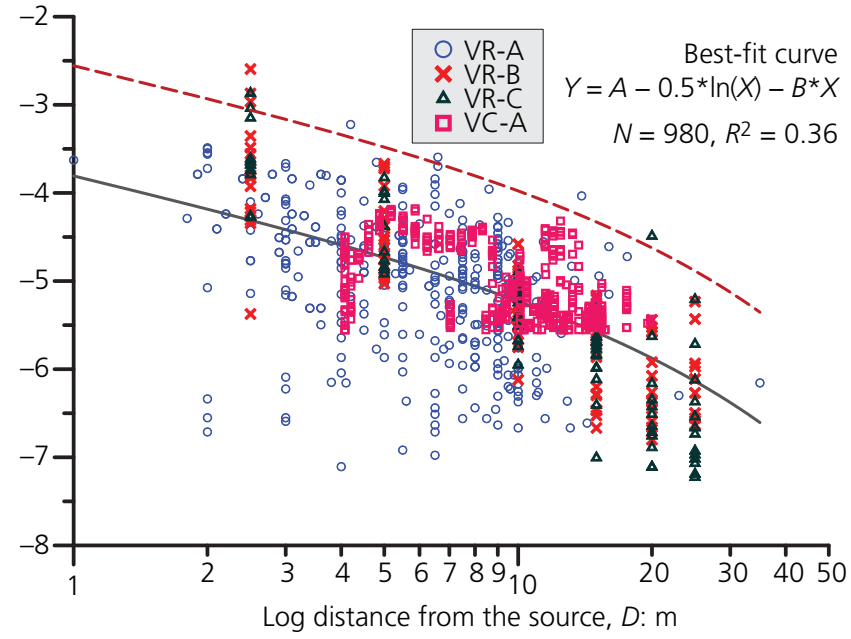

Figure 9. Plot of normalised $P P V_{R}$ against distance from the source for the different vibrators (general regression)

and by replacing the unknowns with the computed values, can be given as

$$
\left(\frac{P P V_{\mathrm{R}}}{\sqrt{E_{\mathrm{r}} / M}}\right)_{@ 50 \%}
$$

14a. $=0.025 \times D^{-0.50} \times \exp (-0.030 \times D)$

The upper bound curve, which corresponds to a confidence level of $97.7 \%$ against exceedance, can be estimated on the basis of the computed statistical parameters, such as the standard deviation of the data set. The upper bound curve can then be given as

$$
\left(\frac{P P V_{\mathrm{R}}}{\sqrt{E_{\mathrm{r}} / M}}\right)_{@ 97.7 \%}
$$

14b. $=0.08 \times D^{-0.50} \times \exp (-0.030 \times D)$

The calculated modification factor of about 3.2 to convert Equation $14 \mathrm{a}$ to Equation $14 \mathrm{~b}$ is observed to be similar to the factor suggested by Hiller and Crabb (2000) to convert a 50\% confidence level to a $95 \%$ confidence level (2.88). Similarly, Achmus et al. (2010) have a factor of about 2.55 to convert a $50 \%$ confidence level to a $97.7 \%$ confidence level on the basis of the resultant ground $P P V$.

Because the $P P V$ equation has been reduced to distance- and vibrator-dependent variables according to Equations $14 \mathrm{a}$ and $14 \mathrm{~b}$, one can easily apply it to practical use, as shown in the next section.

Alternatively, as the material damping factor is frequency dependent and because deep vibro-technique solutions are applicable to different soil types, the material damping can be expressed as

$15 a$.

$$
\ln \left(\frac{P P V_{\mathrm{R}}}{\sqrt{E_{\mathrm{r}} / M}}\right)=\ln \Psi-0.5 \times \ln D-\frac{\pi \eta}{c} \times f_{\mathrm{o}} \times D
$$

where the coefficient $\eta$ is the material damping loss factor, $c$ is the wave speed relevant to the type of wave under consideration and $f_{\mathrm{o}}$ is the vibrator frequency (in $\mathrm{Hz}$ ). The corresponding expressions for the $50 \%$ and $97.7 \%$ confidence levels against exceedance can then be written as

$$
\left(\frac{P P V_{\mathrm{R}}}{\sqrt{E_{\mathrm{r}} / M}}\right)_{@ 50 \%}
$$

15b. $=0.025 \times D^{-0.50} \times \exp \left(-\pi \times \frac{f_{o}}{c / \eta} \times D\right)$

$$
\begin{aligned}
& \left(\frac{P P V_{\mathrm{R}}}{\sqrt{E_{\mathrm{r}} / M}}\right)_{@ 97.7 \%} \\
& =0.025 \times D^{-0.50} \times \exp \left(-\pi \times \frac{f_{o}}{c / \eta} \times D\right)
\end{aligned}
$$

15c. $\times \exp \left(2 \times \sigma_{\text {std }}\right)$

Equations $15 \mathrm{~b}$ and $15 \mathrm{c}$ can be applied to any specific site where the ground parameters (e.g. $c$ and $\eta$ ) and installation parameters (e.g. $f_{\mathrm{o}}, E_{r}, M$ and $D$ ) are identified. These equations can also be plotted separately for vibro-replacement and vibro-compaction projects, as shown in Figure 10. Through regression, the value of the ground parameter $c / \eta$ can be evaluated and compared with the typical values for the ground conditions. The values of $c / \eta$ computed from regression were similar - that is, approximately 3500 and $4000 \mathrm{~m} / \mathrm{s}$ for vibro-compaction and vibro-replacement, respectively. For vibro-replacement works, where most of the ground improvement is carried out in weak cohesive materials, the typical values for the loss factor, $\eta$, are 0.30 (silty) to 0.50 (clayey), whereas for vibro-compaction applications in sand, the typical value of $\eta$ is 0.10 (Gutowski and Dym, 1976). Using these values, it would be evident that the appropriate wave speed $c$ should be the longitudinal wave velocity.

\section{Effect of vibration on nearby structures}

It is to be noted that the potential of damage to structures is due to not only the $P P V$ and frequency but also the duration of the vibration and repetitive exposure. Structural damage can also be due to resonant structure response, structure vibration due to transmitted ground vibrations, dynamic settlements of the ground and accumulated strains from repetitive vibrations (Svinkin, 2004). 


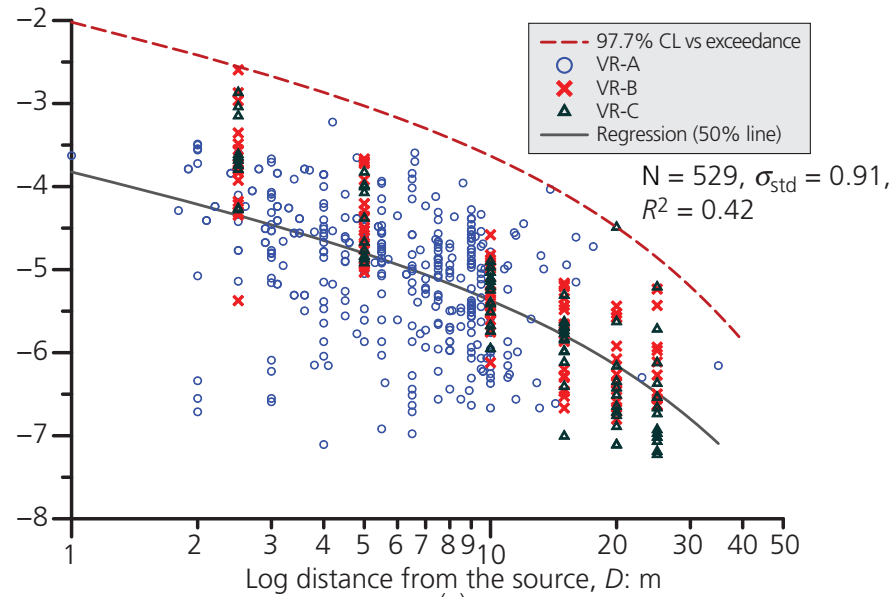

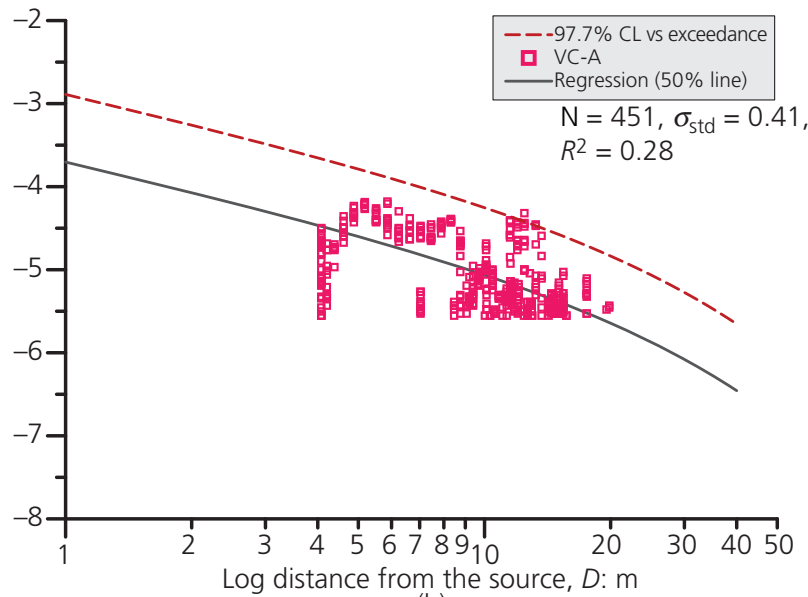

(b)

Figure 10. Plot of normalised $P P V_{R}$ for (a) vibro-replacement and (b) vibro-compaction works

The potential of damage due to vibration is also dependent on how susceptible the structure is to damage to begin with. Recommendations for structure vibration can be taken from BS 5228-2 (BSI, 2008), and the vibration impact threshold, as elaborated in BS 7385-2 (BSI, 1993), can be followed. BS 5228-2 also discusses methods of vibration mitigation, which will not be discussed in this paper. It is also evident from the codes of practice that the damage to structures can be either cosmetic damage (within the serviceability limit state) or structural damage (leading to an ultimate limit state). However, in this paper, a distinction is not made between these, as either can lead to an interruption of the works and potential damage claims. Figure 11 shows the definition of the allowable vibrations as per the different codes mentioned in Table 3.

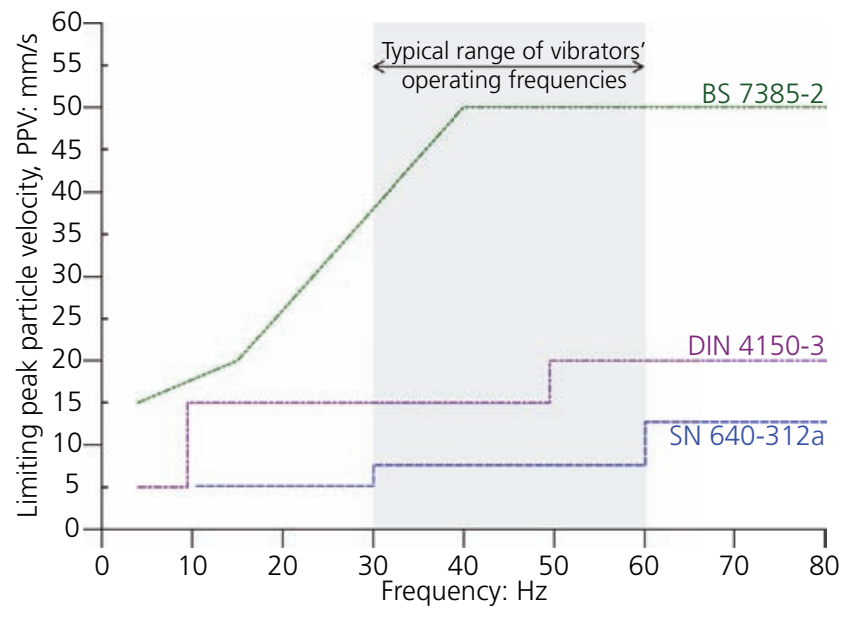

Figure 11. Comparison of limiting PPV and corresponding frequencies from different codes of practice considering a lightframed residential building (modified after Hiller and Crabb (2000))
It is to be noted that the recommendations of the codes, as shown in Figure 11, are for transient vibrations. To assess the potential effect on structures from accumulated strains due to repetitive or continuous vibrations, one can follow the recommendations of many codes of practice that recommend reducing the limiting $P P V$ by a factor of 1.5 to 2.5 (BS 7385-2 (BSI, 1993), BS 5228-2 (BSI, 2008) and DIN 4150-3 (DIN, 2016)).

As the extensive study done by Massarsch (2002) shows, the resonance frequency for most of the soils will be typically in the range of 10 to $20 \mathrm{~Hz}$. From Table 2, it can be observed that the operating frequency of the depth vibrators considered in this study is in the range of 30 to $60 \mathrm{~Hz}$. Thus, it is not likely to cause soil resonance with deep vibro-techniques, and hence, the risk of consequential effect or amplification effects to the surrounding structures is insignificant. The relatively high vibration frequencies from deep vibro-techniques also have the benefit of corresponding higher allowable $P P V \mathrm{~s}$, due to the lower probability of damage from higher frequency vibrations. In this section, the effect on structures due to transmitted vibrations from deep vibro-techniques will be discussed.

Focusing on the structural damage due to transmitted vibrations, if the allowable $P P V$ is given, then the corresponding distance for a chosen confidence level can be computed on the basis of Equation 14a for the preferred confidence level. Figure 12 shows the plot of recommended distances from the source following Equation 14b in order to have $P P V$ values with a $97.7 \%$ confidence level against exceedance.

Some examples from typical practice and site conditions can be considered to illustrate the use of Figure 12. Four such examples are shown in Table 4. In all the cases, the vibration threshold taken is based on repetitive vibrations on the structure, not the transient or onefold vibration limits. Table 4 also includes comparisons of Equations 14a and 14b with the other selected predictive models from Table 1, namely, using Wiss (1981), Ko 


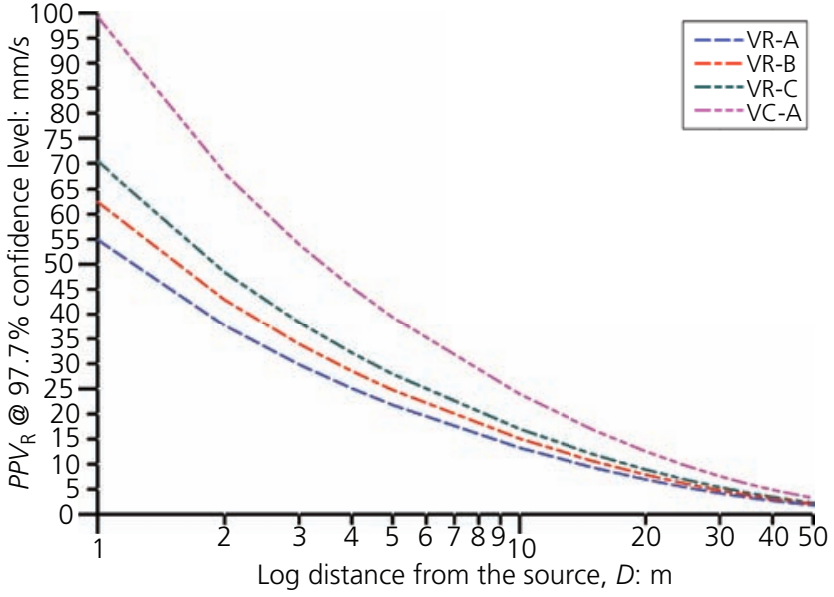

Figure 12. Plot of recommended distance from the source to give $P P V_{R}$ at $97.7 \%$ confidence level against exceedance for different vibrators

et al. (1990) and Attewell et al. (1992a, 1992b). From the table, it is evident that the estimates from these predictive models are not in line with the proposed approach. Wiss (1981), which is a 50\% regression line, gives conservative results for the near-field and optimistic estimates for the far-field. The $97.7 \%$ confidence level prediction approach by Attewell et al. (1992a, 1992b) also yields similar results. Moreover, this approach also gives unrealistic results in the far-field, where the vibration estimates for bigger and more powerful vibrators are smaller than those from less powerful vibrators. Although the approach by Ko et al. (1990) has its merits in considering material damping, it is not sensitive to the type of vibrator or to differences in operating power. As such, as the examples in Table 4 demonstrate, the proposed semiempirical predictive models are useful tools for deep vibrotechniques.

The evaluations in Table 4 also do not consider the effect of dynamic settlements on the structure, which can be detrimental, especially at close range. The inclusion of $50 \%$ and $97.7 \%$ confidence level distances is for comparison purposes. The adoption of the $D_{@} 50 \%$ distances is not recommended as the likelihood of exceedance is high. The $D_{@}$ 97.7\% distances are the recommended distances where deep vibro-techniques can be executed safely.

Table 4. Examples of recommended safe distances for depth vibrator operations

\begin{tabular}{|c|c|c|c|c|c|}
\hline \multirow[t]{2}{*}{ Examples considered for evaluation } & \multirow[t]{2}{*}{ Method } & \multicolumn{4}{|c|}{$\begin{array}{l}\text { Estimated safe operating distances } \\
\text { for different vibrator types: } m\end{array}$} \\
\hline & & VR-A & VR-B & VR-C & VC-A \\
\hline \multirow{6}{*}{$\begin{array}{l}\text { Reinforced or framed structures, industrial and heavy } \\
\text { commercial buildings } \\
\text { (PPV of } 25 \mathrm{~mm} / \mathrm{s} \text { ) }\end{array}$} & Estimated $D_{@ 50 \%}$ & 1.0 & 1.0 & 1.0 & 2.0 \\
\hline & Proposed $D_{@ 97.7 \%}$ & 4.0 & 5.0 & 6.0 & 10.0 \\
\hline & Wiss (1981) & 1.0 & 2.5 & 3.5 & 3.5 \\
\hline & $\begin{array}{l}\text { Attewell et al. (1992a, 1992b) } \\
\text { (97.7\% estimate) }\end{array}$ & 5.5 & 13.0 & 16.0 & 18.5 \\
\hline & Ko et al. (1990) & 2.0 & 2.0 & 2.0 & 2.0 \\
\hline & Modified & & & & \\
\hline \multirow{5}{*}{$\begin{array}{l}\text { Unreinforced or light framed structures }(10 \mathrm{~mm} / \mathrm{s} @ 15 \mathrm{~Hz} \\
\text { increasing to } 25 \mathrm{~mm} / \mathrm{s} @>40 \mathrm{~Hz} \text { ) }\end{array}$} & Estimated $D_{@ 50 \%}$ & 1.0 & 1.0 & 1.0 & 2.5 \\
\hline & Proposed $D_{@} 97.7 \%$ & 4.0 & 5.0 & 6.0 & 13.5 \\
\hline & Wiss (1981) & 1.0 & 2.5 & 3.5 & 4.5 \\
\hline & $\begin{array}{l}\text { Attewell et al. (1992a, 1992b) } \\
\text { (97.7\% estimate) }\end{array}$ & 5.5 & 13.0 & 16.0 & 22.0 \\
\hline & Ko et al. (1990) & 2.0 & 2.0 & 2.0 & 3.0 \\
\hline \multirow{6}{*}{$\begin{array}{l}\text { Underground services, metal and reinforced concrete pipes } \\
\text { (PPV of } 15 \mathrm{~mm} / \mathrm{s} \text { ) }\end{array}$} & Estimated $D_{@ 50 \%}$ & 1.5 & 2.0 & 2.5 & 4.0 \\
\hline & Proposed $D_{@} 97.7 \%$ & 9.0 & 10.0 & 12.0 & 17.0 \\
\hline & Wiss (1981) & 1.5 & 4.0 & 5.0 & 5.5 \\
\hline & $\begin{array}{l}\text { Attewell et al. (1992a, 1992b) } \\
\text { (97.7\% estimate) }\end{array}$ & 12.0 & 20.0 & 22.0 & 25.0 \\
\hline & Ko et al. (1990) & 4.5 & 4.5 & 4.5 & 4.5 \\
\hline & Modified & & & & \\
\hline \multirow{5}{*}{$\begin{array}{l}\text { Historical monuments, old and statically undefined structures } \\
(P P V \text { of } 5 \mathrm{~mm} / \mathrm{s})\end{array}$} & Estimated $D_{@} 50 \%$ & 8.0 & 9.5 & 11.0 & 16.0 \\
\hline & Proposed $D_{@} 97.7 \%$ & 26.5 & 29.0 & 32.0 & 40.0 \\
\hline & Wiss (1981) & 5.5 & 9.5 & 11.0 & 15.0 \\
\hline & $\begin{array}{l}\text { Attewell et al. (1992a, 1992b) } \\
\text { (97.7\% estimate) }\end{array}$ & 70.0 & 60.0 & 45.0 & 35.0 \\
\hline & $\begin{array}{l}\text { Ko et al. (1990) } \\
\text { Modified }\end{array}$ & 16.0 & 16.0 & 16.0 & 16.0 \\
\hline
\end{tabular}

Note: these are examples illustrating the application of the semi-empirical approach shown in Figure 9 . The inclusion of distances $D_{@} 50 \%$ and $D_{@} 97.7 \%$ is for comparison purposes and to highlight the effect of the distance from the source on the exceedance rate. It is also important to note that the above estimations consider only a structure vibration transmission case, and no allowance is made for dynamic settlement effects due to the vibration action (especially for close-range cases) 


\section{Conclusions and recommendations}

For this paper, a total of about 1000 data points were collected and analysed from different types of depth vibrators for both vibroreplacement and vibro-compaction works. The applicabilities of the different $P P V$ estimation approaches were checked on the basis of the gathered data. A semi-empirical approach was developed for evaluating the $P P V$ due to different types of depth vibrators. The approach that was developed considers both material and geometric damping. Recommendations for both damping modes were made on the basis of factors developed from regression analyses. Simplified expressions for the normalised $P P V$ were made as a function of distance from the source.

The analyses contained in this paper do not consider the effects of dynamic settlements and accumulated strains due to repetitive vibrations. It was also demonstrated that resonant frequency failures of structures are not likely to happen for vibro-technique works. For structure failure due to vibration transmission, following the code provisions for vibration-related damage threshold and a higher safety margin by considering a confidence level against exceedance is recommended. A confidence level of $97.7 \%$, or two standard deviations higher than the mean $P P V$, is considered to be an adequate safety margin against potential impact.

Although estimations in the form of $P P V$ and distance from the source are given, it should not be construed that the potential damage of structures is purely reliant on these two parameters only. These estimations are reduced to their current forms for the sake of simplicity and for the depth vibrators covered in this study.

\section{REFERENCES}

AASHTO (American Association of State Highway and Transportation Officials) (2009) R8-96: Standard recommended practice for evaluation of transportation-related earth borne vibrations. AASHTO, Washington, DC, USA.

Achmus M, Wehr W and Spannhoff T (2010) Building vibrations due to deep vibro processes. 7th Conference on Ground Improvement Techniques, Seoul, South Korea.

Amick H and Gendreau M (2000) Construction vibrations and their impact on vibration-sensitive facilities. In Construction Congress VI: Building Together for a Better Tomorrow in an Increasingly Complex World (Walsh KD (ed.)). American Society of Civil Engineers, Reston, VA, USA, pp. 758-767.

Attewell PB and Farmer IW (1973) Attenuation of ground vibrations from pile driving. Ground Engineering 63(7): 26-29.

Attewell PB, Selby AR and O'Donnell L (1992a) Estimation of ground vibration from driven piling based on statistical analyses of recorded data. Geotechnical \& Geological Engineering 10(1): 41-59, https:// doi.org/10.1007/BF00881970.

Attewell PB, Selby AR and O'Donnell L (1992b) Tables and graphs for the estimation of ground vibration from driven piling operations. Geotechnical \& Geological Engineering 10(1): 61-85, https://doi.org/ 10.1007/BF00881971.

BRE (Building Research Establishment) (1995) Digest 403: Damage to Structures from Ground-borne Vibration. Building Research Establishment, Watford, UK.

BSI (1993) BS 7385-2: Evaluation and measurement for vibration in building: Part 2: a guide to damage levels from ground - borne vibration. BSI, London, UK.
BSI (2005) BS EN 14731: Execution of special geotechnical works ground treatment by deep vibration. BSI, London, UK.

BSI (2008) BS 5228-2: Code of practice for noise and vibration control on construction and open sites. Part 2: vibration. BSI, London, UK.

Chua TS, Seah YT, Chew WK and Gary N (2009) Soil improvement using vibroflotation close to buried structures. In Ground Improvement Technologies and Case Histories (Leung CF, Chu J and Shen RF (eds)). Research Publishing Services, Singapore, pp. 389-394.

Deckner F, Viking K and Hintze S (2017) Wave patterns in the ground: case studies related to vibratory sheet pile driving. Geotechnical and Geological Engineering 35(6): 2863-2878, https://doi.org/10.1007/ s10706-017-0285-x.

DGMS (Directorate General of Mines Safety) (1997) Damage of the Structures Due to Blast Induced Ground Vibration in the Mining Areas (Circular No. 7). DGMS, Dhanbad, India.

DIN (German Institute for Standardization) (2016) DIN 4150-3: Structural vibration - part 3: effects of vibration on structures. DIN, Berlin, Germany.

Ekanayake SD, Liyanapathirana DS and Leo CJ (2013) Influence zone around a closed-ended pile during vibratory driving. Soil Dynamics and Earthquake Engineering 53: 26-36, https://doi.org/10.1016/j. soildyn.2013.06.005.

Gutowski TG and Dym CL (1976) Propagation of ground vibration: a review. Journal of Sound and Vibration 49(2): 179-193, https://doi. org/10.1016/0022-460X(76)90495-8.

Hamidi A, Farshi Homayoun Rooz A, Pourjenabi and M (2018) Allowable distance from impact pile driving to prevent structural damage considering limits in different standards. Practice Periodical on Structural Design and Construction 23(1): article 04017029, https:// doi.org/10.1061/(ASCE)SC.1943-5576.0000354.

Hiller DM and Crabb GI (2000) Ground Borne Vibration Caused by Mechanised Construction Works. Report 429. Transport Research Laboratory, Crowthorne, UK.

Ho CE and Tan CG (2003) Vibrations due to driving of large displacement concrete piles in residual granitic soils. In Field Measurements in Geomechanics (Myrvoll F (ed.)). Balkema, Lisse, the Netherlands, pp. 111-116.

Ko JM, Luk ST and CY Cheng (1990) Ground vibrations induced by driving concrete piles. In Australian Vibration and Noise Conference 1990: Vibration and Noise-measurement Prediction and Control. Institution of Engineers Australia, Barton, ACT, Australia, pp. 245-249.

Long PD (1989) Effects of Vibrations From Pile Driving on Surrounding Ground and Structures. SGI Varia 251. Swedish Geotechnical Institute, Linköping, Sweden.

Massarsch KR (2002) Effects of vibratory compaction. Keynote Lecture. In Vibratory Pile Driving and Deep Soil Compaction (TRANSVIB 2002) (Holeyman A, Vanden Berghe JF and Charue N (eds)). Balkema, Lisse, the Netherlands, pp. 33-42.

Mintrop L (1911) Über die Ausbreitung der von den Massendrucken einer Großgasmaschine erzeugten Bodenschwingungen. PhD thesis, GeorgAugust-Universität Göttingen, Göttingen, Germany (in German).

SIS (Swedish Institute for Standards) (1999) SS 0252 11: Vibration and shock - guidance levels and measuring of vibrations in buildings originating from piling, sheet piling, excavating and packing to estimate permitted vibration levels. SIS, Stockholm, Sweden (in Swedish).

Siskind DE, Stagg MS, Kopp JW and Dowding CH (1980) Structure Response and Damage Produced by Ground Vibrations from Surface Blasting. Report of Investigation 8507. U.S. Bureau of Mines, Washington, D.C., USA.

SNV (Swiss Association for Standardization) (1992) SN 640-312: Vibrations - vibration effects in buildings. SNV, Winterthur, Switzerland.

Svinkin MR (2004) Minimizing construction vibration effects. Practice Periodical on Structural Design and Construction 9(2): 108-115, https://doi.org/10.1061/(ASCE)1084-0680(2004)9:2(108). 


\section{Geotechnical Research}

Volume 7 Issue 4
Data analysis and prediction of ground vibrations due to deep vibro-techniques Weng, Yohannes and Chong
Wiss JF (1967) Damage effects of pile driving vibration. Highway Research Record 155: 14-20.

Wiss JF (1981) Construction vibrations: state-of-the-art. Journal of Geotechnical and Geoenvironmental Engineering 107(2): 167-181.
Woods RD and Jedele LP (1985) Energy-attenuation relationships from construction vibrations. In Vibration Problems in Geotechnical Engineering (Gazetas G and Selig ET (eds)). ASCE, New York, NY, USA, pp. 229-246.

\section{How can you contribute?}

To discuss this paper, please submit up to 500 words to the editor at journals@ice.org.uk. Your contribution will be forwarded to the author(s) for a reply and, if considered appropriate by the editorial board, it will be published as a discussion in a future issue of the journal. 